the Scandinavian ice to England, and the rapid collapse of the ice-sheets at the close of the Quaternary glaciation, are accounted for by this effect. A floating polar ice-cap can be dealt with in the same way; at the close of a warm period the ocean will remain entirely free of ice until the temperature falls to freezing-point in winter. A small further fall, and a floating ice-cap will spread over the whole of the polar ocean. Kerner's and Brooks's calculations indicate that a general rise of temperature by $5^{\circ} \mathrm{F}$. persisting over many years would suffice to render the whole Arctic Ocean nonglacial, a change which would reverberate over the whole globe.

This idea entirely alters the scale of the problem. Many factors which are inadequate to account for the temperature change of some $40^{\circ} \mathrm{F}$. in the polar and cold temperate regions between an ice-age and a warm period may easily account for a change of $10^{\circ} \mathrm{F}$., the remaining $30^{\circ}$ being due to the cooling power of land ice and sea ice. Only two types of climate are possible, the 'non-glacial' or warm and the 'glacial' or cold. The transition from one to the other may be due to any of the climatic factors which have been so ardently advocated, but the close association between cold climates and mountain-building suggests the dominance of geographical causes. After a major orogenic period the continents are high and extensive, the ocean currents are restricted, and perhaps volcanoes send out large quantities of dust to interfere with the free passage of the sun's rays ; all these causes, combined perhaps with unfavourable astronomical conditions, lower the amount of heat reaching high latitudes, so that the temperature of the polar oceans falls below the freezing-point in winter and a floating ice-cap is formed. After a long period of rest and erosion, the continents are low and small, there is a free oceanic circulation, and volcanoes are unknown; so much heat reaches high latitudes that the polar oceans are above the freezingpoint even in winter, and there is no ice.

What of the Upper Carboniferous glaciation of the tropics? The geographical theory can be indicated only briefly ; it postulates a high plateau, with a cold ocean to the south, a warm ocean to the north, and a permanent 'south-west monsoon' blowing from the former to the latter, covering the plateau with a dense layer of low cloud which with the assistance of a volcanic dust veil reflected a large proportion of the sun's rays back to space and kept the temperature low enough for snow to fall abundantly above a level of about 6000 feet, giving rise to ice-sheets which reached the sea. Whether the difficulties which confront this theory are greater than those confronting the theory of continental drift which is its only alternative, time will show.

\title{
Recent Developments in the University of Sheffield.
}

$\mathrm{O}^{\mathrm{N}}$ July $I$ and 2 the University of Sheffield celebrated the twenty-first anniversary of the granting of its charter of incorporation. Congratulatory addresses were presented by sister universities throughout Great Britain and the Dominions, scientific and other institutions and societies, and public bodies. Among the recipients of honorary degrees may be mentioned H.R.H. Princess Mary, Lord Derby, Sir Austen Chamberlain, Sir Charles Eliot, Prof. P. F. Frankland, and Engineer Vice-Admiral Sir Robert B. Dixon. New engineering and metallurgical laboratories were formally opened by Sir Robert Hadfield, and the numerous delegates and other visitors were afforded an opportunity of acquainting themselves with the work of the various departments.

The University of Sheffield received its charter twenty-one years ago, but the history of the institutions out of which it grew goes back much further. The Technical School, the germ of the present Applied Science Department, was founded in 1886 ; Firth College, from which the faculties of arts and pure science took their origin, dates from 1879 ; while the Medical School will be able to celebrate its centenary in I928. These three institutions united in 1897 to form the University College of Sheffield, which received full university status in 1905 . The history of the University during the past twenty-one years has been one of almost unbroken progress in every direction. The numbers of its students and staff have greatly increased, especially since the War; the amount of research work carried on within its walls has grown steadily; new departments and courses have been established as the need for them arose and the resources of the University permitted; and generous financial support has been received from private and public sources. Though a complete survey of recent progress is not possible here, a few notes on the main lines of development may perhaps be not without interest.

The most rapid and extensive progress in recent years has taken place in the Department of Applied Science, which includes the faculties of engineering and metallurgy, and a number of associated departments. Expansion in these branches has been made possible largely by the growing recognition in industrial circles of the importance of technical training and scientific research. Thanks to the generous support of leading Sheffield industrialists, the departments of the faculty of engineering have been able to make several important additions to their resources. The Edgar Allen and Jonas Research Laboratories, opened in 1923, are designed respectively for research in magnetism, magnetic properties of materials, and allied subjects, and for investigations on the mechanical properties of materials. Further provision for research in this latter subject has been made in the new laboratory opened by Sir Robert Hadfield on July 2, which is being used at present for work on the effects of high temperatures, heat treatments and repetition stresses, but can be adapted, as the need arises, for the investigation of many other engineering problems. All these new laboratories are equipped with the most modern machines and apparatus, constructed in many cases in the engineering workshops.

One of the most important post-War developments is the establishment, in association with the faculty of engineering, of a Department of Fuel Technology. This

$$
\text { No. 2958, VOL. II } 8]
$$


is essentially a research department, and the majority of its students are honours graduates in chemistry. It co-operates closely with the mining and metallurgical departments, and has entered into a working arrangement with the Safety in Mines Research Board and the Fuel Research Board, whereby the facilities for research work at the disposal of each body are shared mutually, and the respective staffs engage in conjoint work. Among the subjects that have particularly engaged the attention of the department have been the properties and production of blast-furnace coke, the constitution and properties of coal, and problems of gaseous combustion.

The Mining Department, an integral part of the faculty of engineering, has also made rapid progress, especially on the research side of its work, which has dealt chiefly with flame-proof electrical apparatus, coal-cutter steels, winding and haulage ropes, and mine ventilation. The Department has co-operated with the Safety in Mines Research Board and with the mining industry of the surrounding area. Its work has grown to such an extent that the present accommodation is inadequate, and a scheme is in hand for the erection in the near future of an entirely new mining department.

No account of the progress made in applied science would be complete without a reference to the Department of Glass Technology, which is equipped with a complete glass works, and laboratories in which a large body of research has been carried out. In connexion with the Department there has been formed the Society of Glass Technology, with a membership of about $65^{\circ}$, distributed through twenty-two countries.

The faculty of metallurgy has existed separately since 1917 , but the subject has played a leading part in the activities of the Applied Science Department since its earliest days. Owing to the nature of the chief industries of Sheffield, the needs of which it was originally created to serve, the faculty chiefly concentrates on the metallurgy of iron and steel, and it is now the best equipped in the country for work in this sphere. Recently, in response to the growing interest in scientific research among the lighter industries of the city, increasing provision has been made for non-ferrous metallurgy. A notable feature of the activities of the Department is the close association of practical training with theoretical instruction. Its equipment includes a complete steel works, fitted with plant of sufficient capacity to produce open-hearth, crucible and electric steels for the use of both the Metallurgical and Engineering Departments. Recent developments include the provision of a new laboratory designed specially for post-graduate research work on the physical properties of steel, and the institution, with the aid of a grant from the Department of Scientific and Industrial Research, of research work on electrodeposition, which will be of great importance to the Sheffield plating trades. Other Government departments and research associations maintain research workers in the metallurgical laboratories.

Though the rapid expansion of the Applied Science Department has been a notable feature of the recent history of the University, considerable development in other directions can be recorded. There has been a great increase in both teaching and research work in the faculty of pure science. Chemistry has had to extend its laboratory accommodation by the erection of a large hut in the quadrangle, and there has been a steady output of research, carried out largely with the aid of students, which has been concerned mainly with investigations on the reactivity of substituents in the benzene nucleus, the remarkable isomerism of diphenyl derivatives, and adsorption by porous bodies. Physics also has been compelled to provide for its enlarged teaching work by the erection of a hut, and has further acquired four new research rooms. The research work carried out in the Department has followed the line, laid down originally by Emeritus Prof. W. M. Hicks, of specialisation in spectroscopy, and a very considerable equipment in this branch of physical study has been gathered together.

In the faculty of medicine three recent developments are worthy of notice. There have been, in the first place, changes in the curriculum and organisation of the faculty, with the object of bringing both its teaching and research work into closer contact with the city hospitals. Anatomy and physiology, formerly taken for the second M.B., Ch.B. examination, have been extended into the third M.B., Ch.B. course, and thus, during the third and part of the fourth year, theoretical work in these subjects is carried on simultaneously with clinical training. A series of posts in physiology and pathology, the holders of which work both in the University and in the hospitals, has been created. An important part in linking up the teaching work of the University with the clinical part of the medical course is played by the Department of Pharmacology, established in $192 \mathrm{I}$, which has devoted itself to extensive investigations on subjects of combined laboratory and clinical interest. In addition to the accommodation at the University, the Department possesses a field laboratory in the country, specially created for experimental work on nutritional and other problems. The opportunities for medical research provided in the Department have resulted in a large output of work, including amongst other subjects the etiology and treatment of rickets, the factors of diet and environment responsible for the structure of the teeth, conditions controlling the rate of development of caries in children, the treatment of exophthalmic goitre, the action of alcohol and the toxic action of cereals. The third line of development in the medical work of the University has been the reestablishment of the dental school, in connexion with which new laboratories, provided with the most modern equipment for the teaching of dental mechanics, have been opened. A complete course of instruction for degrees and diplomas in dental science has been arranged, and hospital accommodation for clinical work is provided.

The foregoing notes, though they mention only the most important developments of recent years, show that Sheffield has taken its place side by side with the other universities of Great Britain, as an institution actively engaged both in the propagation and in the expansion of knowledge. The main lines of expansion which it is destined to follow are laid down, and further progress may confidently be expected as funds become available.

NO. 2958, VOL. I I 8$]$ 